\section{EL AJUAR DE LA CÁMARA FUNERARIA IBÉRICA DE TOYA (PEAL DE BECERRO, JAÉN) (1)}

\author{
GRAVE GOODS OF THE IBERIAN \\ CHAMBER TOMB OF TOYA \\ (PEAL DE BECERRO, JAEN)
}

\section{ANTONIO MADRIGAL (*)}

\section{RESUMEN}

La cámara funeraria de Toya (Jaén) fué encontrada a principios de siglo, y sus materiales se dispersaron en diversas colecciones. Se presenta aquí por primera vez la reconstrucción y estudio del ajuar completo de esta importante tumba ibérica.

\begin{abstract}
The Iberian chamber tomb of Toya (Jaén, Spain), was found at the beginning of this century, but its grave goods were divided among several collections. This paper offers a complete study of this important find for the first time.
\end{abstract}

Palabras clave: Cultura Ibérica. Tumba de cámara. Ajuar funerario. Toya. Guadiana Menor. Peal de Becerro. Cazorla. J. Cabré. M. Gómez-Moreno.A. Vives.

Key words: Iberian Culture. Chamber tomb. Grave goods. Guadiana Menor Valley. Toya. Peal de Becerro. Cazorla. J. Cabré. M. Gómez-Moreno. A. Vives.

(1) Este trabajo ha sido realizado dentro del Proyecto «Sociedad ibérica en el Sureste español: una perspectiva espacial» (D.G.I.C.Y.T. $\mathrm{n}^{\circ} \mathrm{PB}$ 94-0251).

(*) Departamento de Pehistoria. Universidad Complutense. 28004-Madrid

El artículo fue remitido en su versión final el 18-XI-96.

\section{INTRODUCCIÓN}

La personalidad funeraria del valle del Guadiana Menor en época ibérica reside principalmente en el empleo de cámaras para los enterramientos colectivos, siendo este uno de los rasgos característicos de la zona (Almagro, 1982). Se entiende por cámara toda aquella tumba cuyo acceso debe hacerse desde un plano horizontal y, por consiguiente, atravesando una puerta. Esta, la diferencia de la fosas complejas, que tienen un acceso vertical, aunque la disposición final de los enterramientos y ajuares en ellas depositados recuerden a las cámaras (como en Baza las tumbas 43 y 155 ó de la «Dama»). Según la anterior definición, las cámaras funerarias se localizan en Toya (Cabré, 1925; Mergelina, 1943-44), Castellones de Ceal (Chapa et alii, 1990) y Galera (Cabré y Motos, 1920), aunque también se conoce algún otro ejemplo fuera de la Alta Andalucía, como es el caso de la tumba 22 de la necrópolis de los Villares, en Albacete (Blánquez, 1992: 252) o la citada por A. Fernández de Avilés (1943: 118) de Archena (Murcia).

Su génesis ha sido siempre vinculada con diferentes áreas del Mediterráneo, siendo valoradas como elementos de aculturación. García y Bellido (1935) las relacionó con los mundos griego y etrusco, opciones recogidas por Nicolini (1973: 65) y Blázquez (1960). Será a partir de Fernández de Avilés (1942) cuando se proponga una filiación feno-púnica por paralelos arquitectónicos, siendo ésta la opinión actualmente más extendida (Alma- 


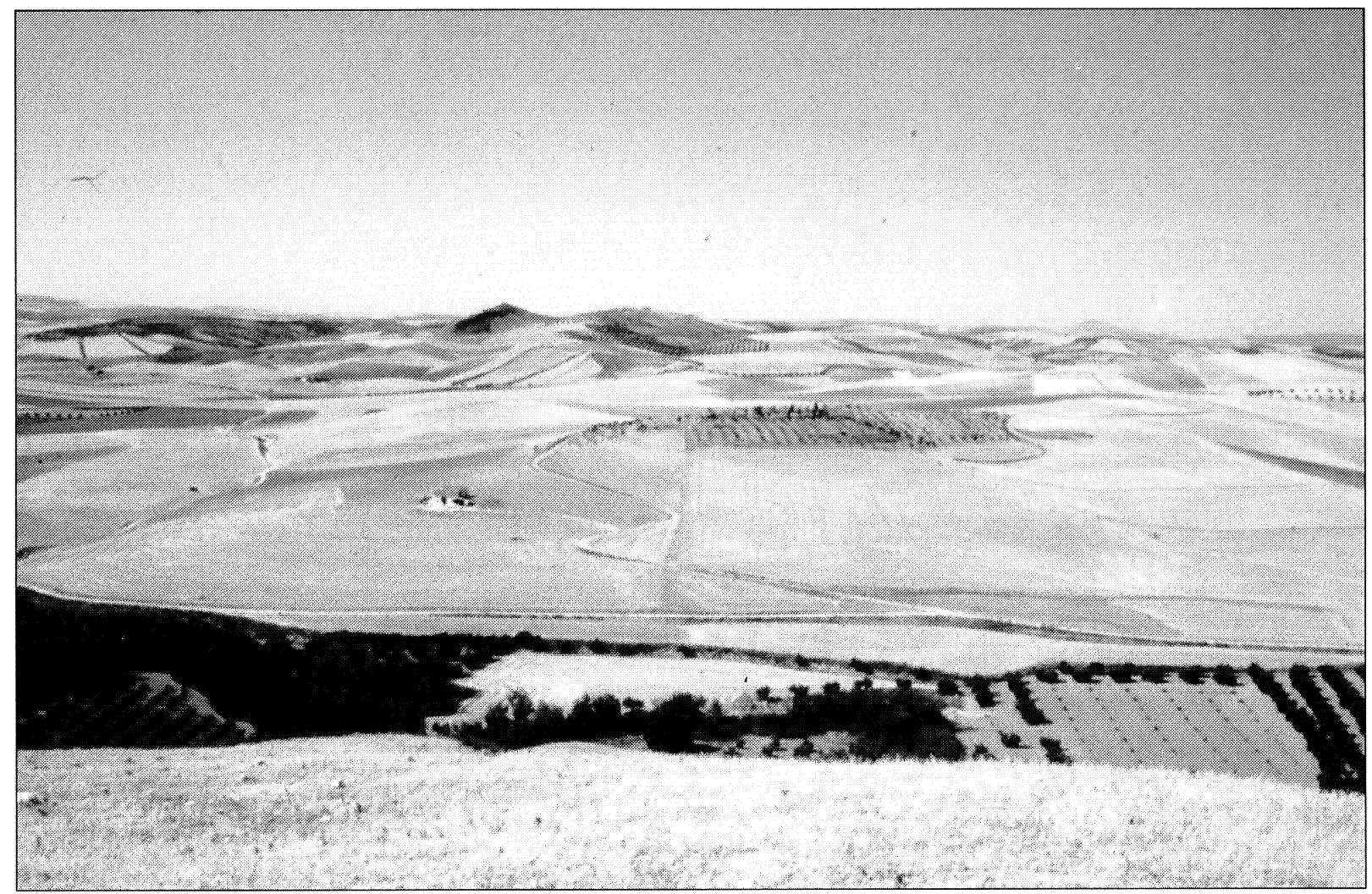

Lám. I. Vista general del Cerro de la Horca; en la cima, la vegetación marca la localización de la cámara.

gro Basch, 1975; Blázquez, 1986: 173; GarcíaGelabert, 1991: 894; Chapa et alii, 1993).

La cronología de estos enterramientos se sitúa a grandes rasgos desde la segunda mitad del siglo V a.C. -datación que tiene la tumba 20 de Galera (Sánchez, 1992: 327)-, hasta el siglo II a.C., que es la cronología propuesta para la tumba $150 \mathrm{del}$ mismo yacimiento.

\section{LA CÁMARA DE TOYA}

De todas las tumbas de cámara se considera la más importante, no sólo por ser la primera en descubrirse y publicarse (Caro Riaño, 1914 y recogido por Cazabán, 1915), sino por su categoría arquitectónica y la gran abundancia y calidad de los materiales cerámicos y metálicos recuperados en su interior. Todo ello, además de su excelente estado de conservación, ha facilitado el acondicionamiento para su visita, encontrándose hoy día abierta al público.

T. P., 54, n. ${ }^{\circ} 1,1997$
Desgraciadamente, la inmediata dispersión de los materiales después de su hallazgo en diversas colecciones particulares, no permitió un buen estudio de conjunto. Las palabras de Mergelina son muy ilustrativas al respecto cuando dice: «Gracias a la cuidadosa rebusca informativa del $\mathrm{Sr}$. Cabré, pudo en gran parte reconstruirse [el ajuar], reseñándose como correspondiente a tan interesante monumento lo que sigue...» (Mergelina, 1943-44: 15). Son muchas las obras que utilizan esta cámara para el estudio de la Cultura Ibérica y de sus hábitos funerarios, pero hasta el momento actual no existía ningún estudio en el que se reunieran las piezas del ajuar original, por lo que éste era insuficientemente conocido. Resultaba, por tanto, imprescindible localizar las piezas mencionadas por Cabré en su trabajo de 1925, y ofrecer un catálogo lo más completo posible de este conjunto.

La «cámara de Toya» es conocida con este nombre en la bibliografía, aunque en la misma necrópolis se documentaron otras tumbas simila- 


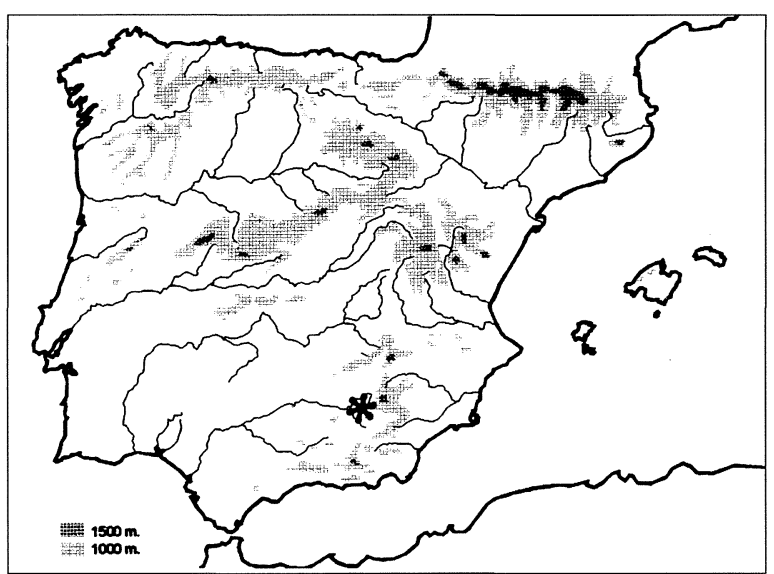

Fig. 1. Localización de Toya.

res (Cabré, 1925: 95; Mergelina, 1943-44: 23-25, fig. 5 y lám. IX). Se ubica en la cota más elevada del Cerro de la Horca, frente a la aldea de Toya en Peal de Becerro, provincia de Jaén (Fig. 1 y Lám. I). Es una construcción de planta cuadrada, de unos $5 \mathrm{~m}$. de lado, con una superficie total aproximada de $25,90 \mathrm{~m}^{2}(2)$. Para su construccción se efectuó una gran fosa excavada en el terreno, rompiendo tumbas anteriores; después de la nivelación se procedió al enlosado y levantamiento de los diferentes muros, terminando de tallar los sillares junto a la obra (Fernández-Miranda y Olmos, 1986: 11-15). Cuando la construción estuvo levantada, se procedió a su cerramiento superior con 28 grandes losas planas (Mergelina, 1943-44: Fig. 1), suponiéndose por sus paralelos en Galera que debió estar cubierta por un túmulo de tierra.

Sobre su acceso, orientado hacia el noroeste, nada se sabe; evidentemente carece de corredor, tan característico de este tipo de enterramiento, y por su sistema de construcción se deduce que debió efectuarse mediante un pozo o una rampa acaso similar a la actual. La cámara consta de una sala principal rectangular a la que se accede directamente desde el exterior descenciendo un escalón. A ambos lados de la entrada tiene sendas puertas - sin hojas- que dan paso a pequeñas habitaciones cuadradas, estas a su vez tienen otra

(2) Este cálculo es apróximado ya que se ignora si el grosor de los muros perimetrales da la planta publicada por Cabré (1925: Fig. 2) es el real, aunque coincide bastante con la presentada por Mergelina (1943-44: Fig. 1).

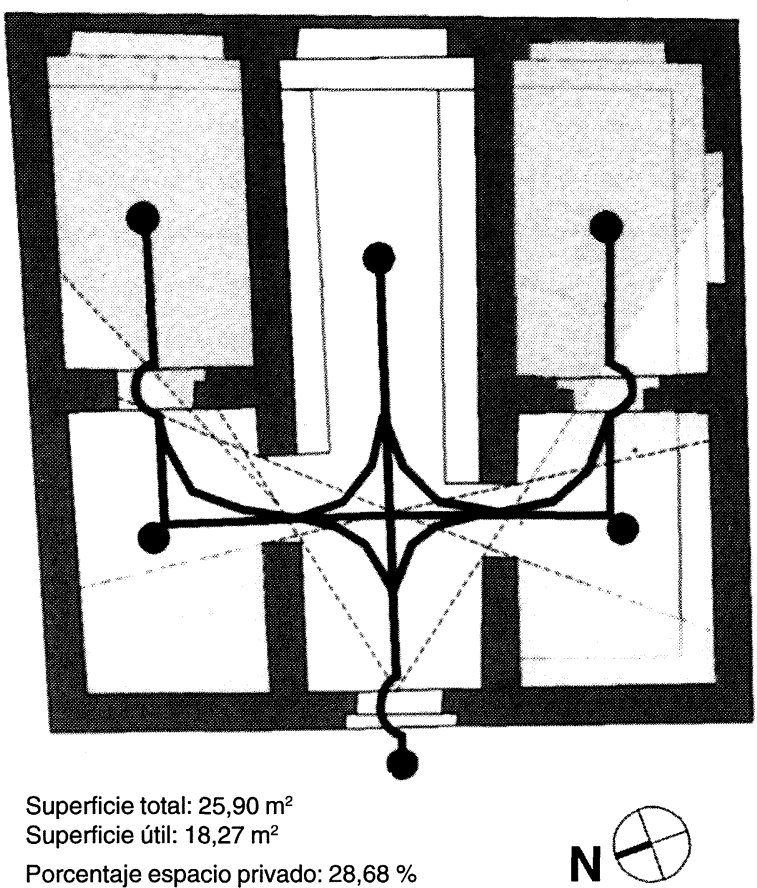

Porcentaje semiprivado: $66,00 \%$

Fig. 2. Planta de la cámara de Toya con los análisis de circulación y visibilidad (dibujo de J. Sánchez).

puerta, sobreelevada y con hoja, que dan acceso a las zonas más profundas y oscuras de la tumba (Fig. 2). En otro lugar (II Congreso de Arqueología Peninsular, celebrado en Zamora en 1996) hemos efectuado un análisis sobre la circulación $\mathrm{y}$ visibilidad en su interior y, como a través de ellos se puede relacionar esta construcción funeraria con los espacios domésticos de la misma época.

\section{BREVE HISTORIA DEL DESCUBRIMIENTO}

Para comprender mejor las vicisitudes pasadas por las diferentes piezas de su interior hay que repasar brevemente la historia de su descubrimiento. Este aconteció hacia 1908 si seguimos a Caro Riaño (Cazabán, 1915: 232), o hacia 1901 si leemos a A. Cazabán (1926: 232), cuando se araba la superficie del cerro. Durante el hallazgo se fracturaron varias piezas cerámicas, mientras que las completas fueron llevadas a Peal de Becerro. Unas quedaron allí (algunos recipientes 
cerámicos y cajas de piedra), mientras que otras fueron vendidas hacia 1909 y/o después (Cabré, 1925: 74-75), a un anticuario de Granada (cerámicas ibéricas y cajas de piedra), a Víctor Linares (cerámicas ibéricas y crátera griega), a Tomás Román Pulido (cerámicas ibéricas), a Emilio Camps Cazorla (escultura), a Pedro García Faria (cerámicas ibéricas) y a Antonio Vives (cerámicas ibéricas) (Bosch, 1913-14). A su vez, parte del lote comprado por el anticuario granadino fue adquirido por Manuel Gómez-Moreno (3) (cerámicas ibéricas), quien vendió una parte a Vives (Bosch, 1913-14) y donará otra parte al Museo de Granada (Eguaras, 1950-51).

El descubrimiento de la tumba fue descrito por Caro Riaño al Marqués de Cerralbo (4) quien enviará a Juan Cabré a estudiar el sepulcro. Este trabajo se realizó en 1918 con datos proporcionados por Gómez-Moreno (Cazabán, 1926: 233; Cabré, 1925: 75), tras concluir las excavaciones de Cabré en los santuarios de Despeñaperros y Castellar de Santisteban, así como en la necrópolis de Galera. La estancia en el lugar del hallazgo y la entrevista con su descubridor permitieron a Cabré adquirir piezas cerámicas completas, no fragmentos, y restos metálicos. El informe elaborado por este autor fue decisivo para que la tumba fuera declarada Monumento Histórico Artístico por Real Orden de 10-VI-1918 (Lainez, 1926; Mergelina, 1943-44: Lám. VII).

Por la notoriedad de ese hecho, el Museo Arqueológico Nacional adquiere en 1917 la escultura de E. Camps y en 1918 la crátera de V. Linares (Mélida, 1919). A esta institución llegarán más piezas cuando adquiera las colecciones de T. Román en 1919, procedentes de sus excavaciones autorizadas por la Junta Superior de Excavaciones y Antigüedades (Román, 1919: 267), de Vives, en 1913; de J. Cabré, después de 1932, y de Julio Martínez Santaolalla, en 1973, todas con piezas de la cámara.

Durante el tiempo transcurrido desde el hallazgo de la cámara hasta 1924, debió sufrir tal deterioro natural y antrópico que A. Cazabán (1926: 233) tuvo que efectuar una inspección en

(3) Vocal de la Junta Superior de Excavaciones y Antigüedades y Conservación de Monumentos Históricos y Artísticos.

(4) Vicepresidente de la Junta Superior de Excavaciones y Antigüedades y Conservación de Monumentos Históricos y Artísticos. calidad de Delegado Regio de Bellas Artes. Su informe sirvió para que la Comisión Provincial de Monumentos Históricos y Artísticos hiciera una primera intervención, llegando a rotular la tumba; en breve tiempo el rótulo fue roto y un vasar de la misma arrancado por rebuscadores de tesoros que, afortunadamente, fueron detenidos y el hecho denunciado a un Juzgado. El informe de Cazaban llegó a Madrid, y la Comisión Provincial de Monumentos Históricos y Artísticos solicitó un guarda que viviera en la vecina aldea de Hornos, para la custodia de la tumba (Cazaban, 1926: 234).

Estos acontecimientos motivaron que la Junta Superior de Excavaciones y Antigüedades, a propuesta de su vocal Gómez-Moreno, solicitara 2000 pts. para la restauración del sepulcro (Cazabán, 1926: 235), encomendándose esta labor a Cayetano de Mergelina, con la colaboración de Juan de Mata Carriazo, Emilio Camps y Juan Muñoz Reja, restauración que concluyó en 1927 (Cazabán, 1928: 337; Mergelina, 1943-44).

En 1985 se procedió a una nueva restauración, en la que tabajaron M. Fernández-Miranda, J.P. Garrido (5) y E. Orta. Durante su realización se abrió una zanja de unos $2 \mathrm{~m}$. de ancho en torno a la cámara, con el fin de rellenarla con hormigón armado para aislarla de la humedad; durante esos trabajos se descubrieron restos de una rueda de carro (Fernández-Miranda y Olmos, 1986). Por esos mismos años se acometío la instalación de un tendido eléctrico y un panel solar para la iluminación del interior de la tumba $\mathrm{y}$, de este modo, facilitar su visita; este panel cumplió poco tiempo su cometido al ser destruido por actos vandálicos de algunos visitantes.

\section{EL AJUAR FUNERARIO RECUPERADO DE LA TUMBA}

Como se vió más arriba, la dispersión de los materiales aparecidos en el interior de la cámara fue inmediata a su descubrimiento. La mayoría pasó a engrosar las colecciones particulares de importantes estudiosos del momento, ya mencionados. Con el paso del tiempo esas colecciones, o parte de las mismas, ingresaron en diferentes

(5) Desde aquí nuestro agradecimiento por facilitarnos información sobre la restauración y excavación. 
museos, a veces perdiendo la referencia de su origen. Otras piezas, por el contrario, se perdieron para siempre. Durante todo ese largo periplo, el material se mezcló con materiales procedentes de otros yacimientos ibéricos -como el Castellar de Santisteban, Archena, Villaricos- y en otros casos sólo conservó de su procedencia los topónimos más importantes y cercanos al de Toya, como Peal o Cazorla. La falta de publicaciones con una buena documentación fotográfica, y de correctas descripciones para los materiales de la cámara, colaboró a su extravío por diferentes museos.

Durante el estudio de los materiales cerámicos y metálicos procedentes de las excavaciones antiguas de Toya, Castellones de Ceal, Galera (6) y Villaricos (7) conservados en distintas colecciones, hemos conseguido identificar las diferentes piezas de la cámara de Toya, empleando la documentación disponible de época antigua y reciente.

\section{CÁTALOGO DE MATERIALES DE LA CÁMARA DE TOYA}

Los materiales que, después de este estudio, consideramos procedentes de la cámara de Toya son los siguientes:

1. Escultura en bulto redondo, tallada en piedra caliza, que representa un herbívoro echado. Falta la cabeza (Lám. II). Este tipo de representación no es desconocido en el Guadiana Menor, pues en la próxima necrópolis de Castellones de Ceal se recuperó un ejemplar muy parecido (Chapa, 1980: 417). Dimensiones: alt.: $38,5 \mathrm{~cm}$.; long.: 52,5 cm.; grosor: $19 \mathrm{~cm}$. Depósito: Museo Arqueológico Nacional, colección E. Camps. Bibliografía: Mélida (1918: 23), Cabré (1925: 85 y Fig. 13), García y Bellido (1963: 582 y Fig. 512), Chapa (1980: 495, fig. 4.94 y Lám. LXXXIV).

2. Crátera de campana de figuras rojas. En su cara A aparece una escena de apoteosis formada por seis personajes; en el centro un varón imber-

(6) Dentro del Proyecto PB 85-0011 de la C.I.C.Y.T. del Ministerio de Educación y Ciencia « Arqueología Funeraria Ibérica: las necrópolis del Guadiana Menor», dirigido por Teresa Chapa y Juan Pereira.

(7) Dentro del Proyecto «Catalogación y Estudio de los fondos de la necrópolis fénico púnica de Villaricos (Almería)», subvencionado por el Plan regional de Investigación de la Comunidad Autónoma de Madrid, y dirigido por Manuel Fernández-Miranda y Alicia Rodero.

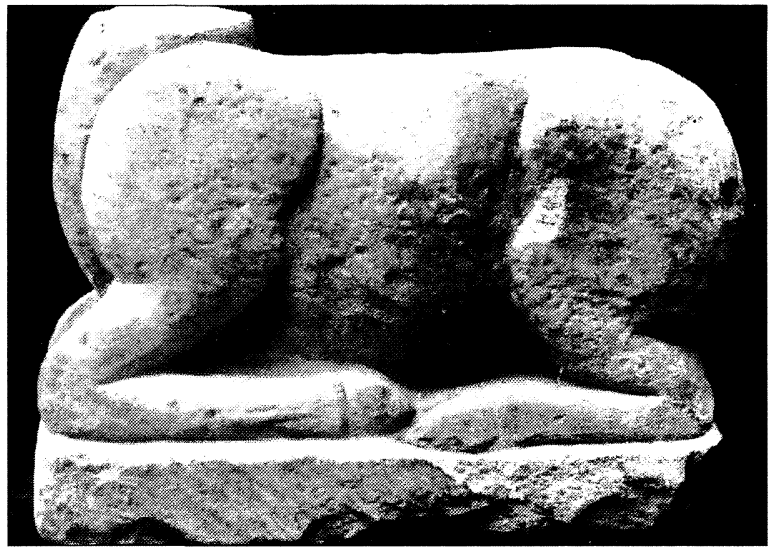

Lám. II. Escultura de cérvido de la cámara de Toya (García y Bellido, 1963).

be, desnudo y sedente sobre su manto vuelve la cabeza, mientras sujeta una vara con la mano es coronado por dos erotes. Detrás otro varón sedente, desnudo y barbado es acompañado por otro joven desnudo. Enfrente una mujer sedente y vestida sostiene en su mano un tirso. En la cara B hay tres jovenes vestidos con himation (Fig. 3, $\mathrm{n}^{\circ} 1$ y 2 y Lám. VII). La pieza ha sido estudiada por C. Sánchez, quien la atribuye al Pintor de Toya y fecha en el segundo cuarto o mediados del siglo IV a.C. Dimensiones: alt.: $42,3 \mathrm{cms}$; diám. boca: 41,2 cms.; diám. base: $17,8 \mathrm{cms}$. Depósito: Museo Arqueológico Nacional, colección Linares. Bibliografía: Mélida (1919: 13-14 y Lám. VI); Cabré (1925: 85-86 y Fig. 15 inferior); García y Bellido (1936: 105 y Lám. LX-44; 1948, II: 185 y Lám. CXLI-4); Trías (1967: 468469 y Láms. CCXXI-2 y CCXXII); FernándezMiranda y Olmos (1986: Láms. 32 y 33); Sánchez (1992: 592-94 y Figs. 88-386 y 89).

3. Dos fragmentos de pared de crátera de campana. Pertenenen a la cara A y muestran, segun C. Sánchez, parte de una escena dionisiaca en la que una mujer en pie sostiene un tirso, detrás se sitúan un sátiro desnudo y una ménade de pie (Fig. $3, n^{\circ} 4$ y Lám. VII). Ha sido atribuida al Pintor de Telos y datada en la primera mitad del siglo IV a.C. Dimensiones: alt.: $12,8 \mathrm{cms}$.; long.: 9,7 cms.; grosor: 0,6 cms. Depósito: Museo Arqueológico Nacional, colección Santaolalla. Bibliografía: Cabré (1925: 87 y Fig. 15 superior izquierda); Fernández-Miranda y Olmos (1986: 143 y Lám. 30-1); Sánchez (1992: 605 y Fig. 96-398).

4. Un fragmento de pared de crátera de cam- 

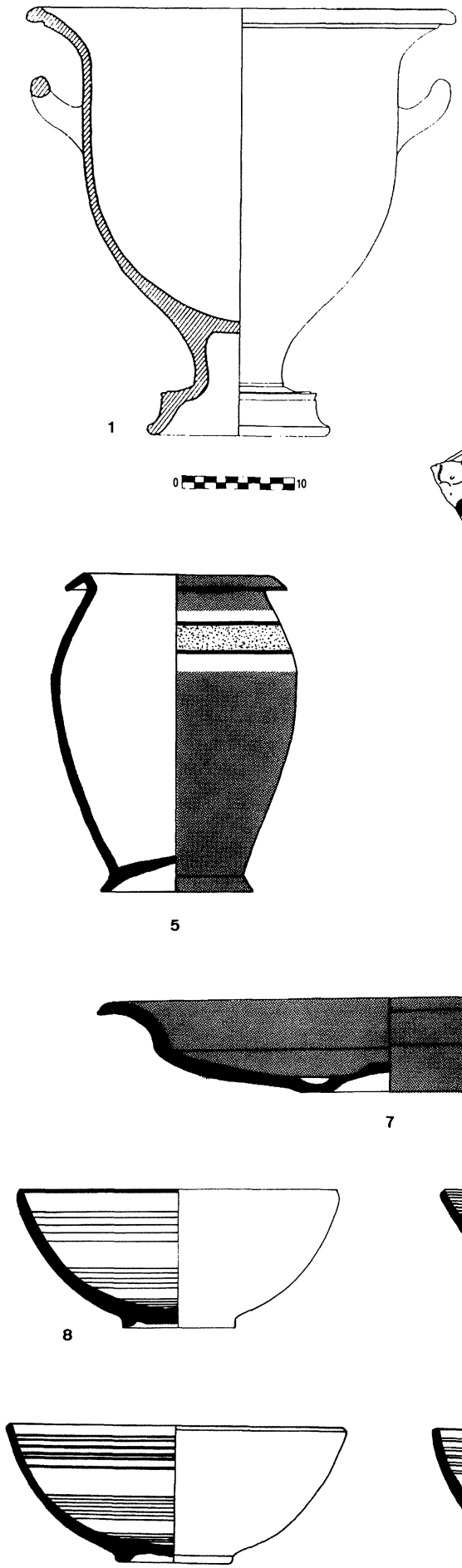

11
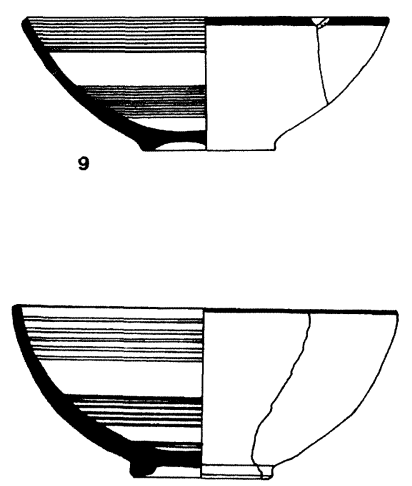

12

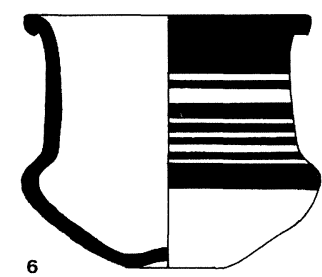

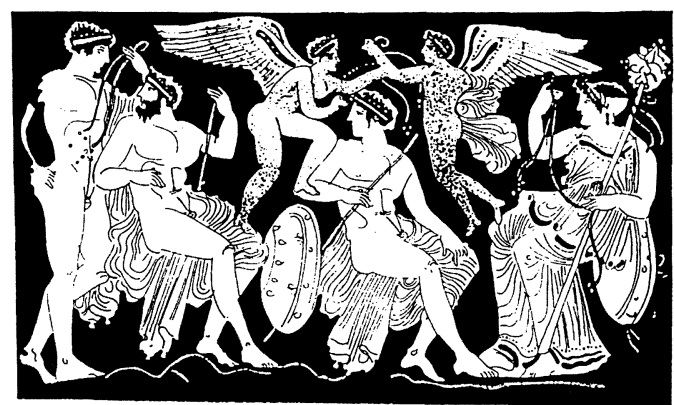
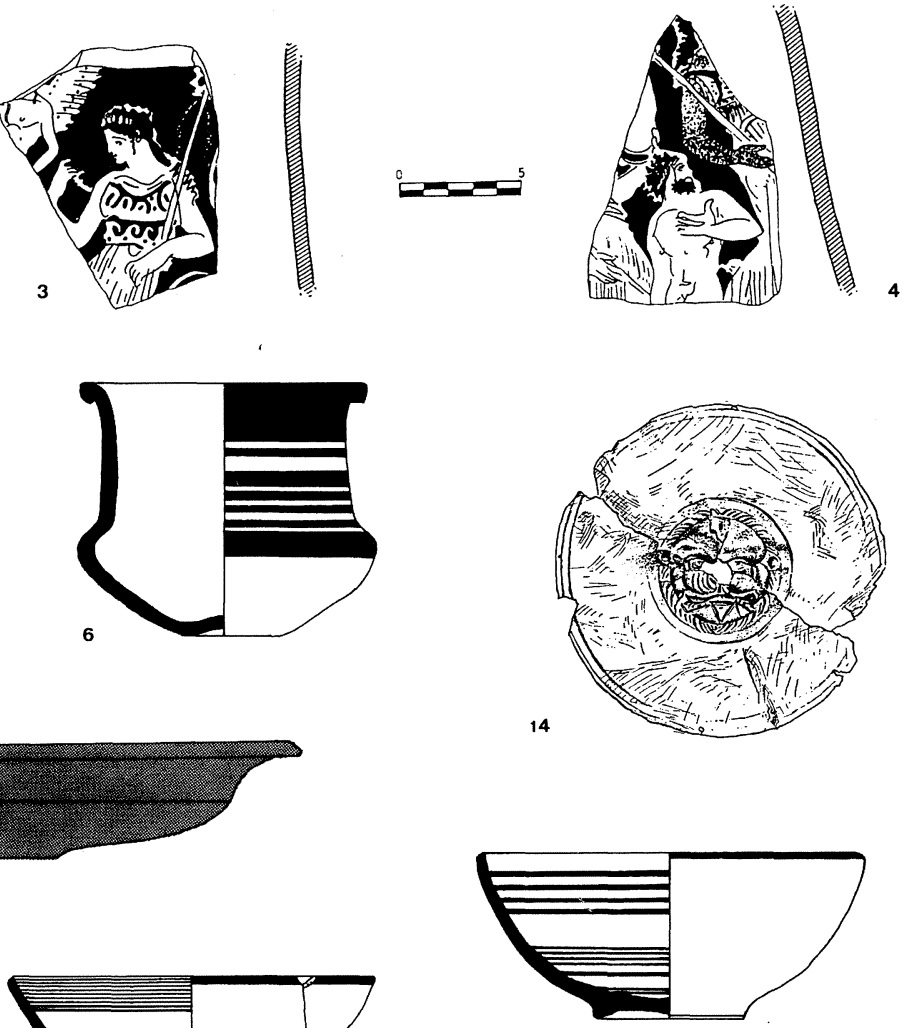

10

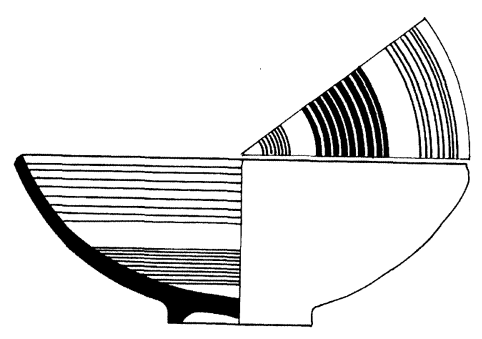

13

Fig. 3. Cerámicas griegas, ibéricas y disco de bronce decorado procedentes de la cámara de Toya (dibujos del autor, excepto 1 y 3: Sánchez, 1992; 5, 6, 7, 14: Cabré, 1925). Los números 2, 5 y 6 sin escala.

T. P., 54, n. ${ }^{\circ} 1,1997$ 
pana. Pertenece a la cara A de la pieza y presenta parte de una escena dionisiaca. Se conserva parte de una mujer sentada ricamente vestida sosteniendo un tirso; a su derecha aparece un Eros alado (Fig. 3, nº 3 y Lám. VII). C. Sánchez lo atribuye al Pintor de la Grifomaquia de Oxford y fecha en la primera mitad del siglo IV a.C. Dimensiones: alt. $9 \mathrm{cms}$; long. $11 \mathrm{cms}$; grosor: $0,6 \mathrm{cms}$. Depósito: Museo Arqueológico Nacional, colección Santaolalla. Bibliografía: Cabré (1925: 86 y Fig. 15 superior derecha); Fernández-Miranda y Olmos (1986: 145 y Lám. 30-2); Sánchez (1992: 606-607 y Fig. 96-399).

5. Dos asas de un kylix, en paradero desconocido. Bibliografía: Cabré (1925: 87).

6. Urna ibérica de borde exvasado, cuello estrangulado, cuerpo globular bitroncocónico y base hundida, tiene una decoración pintada de color vinoso, distibuida en tres bandas horizontales en los dos tercios superiores que enmarcan dos frisos de semicírculos concéntricos separados por rizos verticales (Fig. 4, n ${ }^{\circ} 1$ y Lám. III, n 1 ). Pertenece al tipo 7-A de Pereira (1988: 940 y 943), que fecha en los siglos IV-III a.C., y con paralelos en la tumba 5/617 de Castellones de Ceal (Chapa y Pereira, 1991a: 307; 1991b: 169). Dimensiones: alt.: 30 cms.; diám. boca: 14,6cms.; diám. base: 8 cms. Depósito: Museo Arqueológico Provincial de Granada, colección Gómez-Moreno. Bibliografía: Cabré (1925: 88 y Fig. 19-a); Eguaras (1950-51: $181, n^{\circ} 17$ y Fig. 116-a); Pereira (1988: 336, Fig. 72-1).

7. Urna ibérica con borde exvasado, cuello estrangulado, cuerpo globular, ligeramente bitroncocónico y base hundida, que presenta una decoración pintada de color vinoso que muestra tres finas bandas horizontales que enmarcan dos frisos formados por semicírculos concéntricos separados por rizos verticales (Fig. 4 , no 2 y Láms. IV y VII). Ha sido publicada como de Archena (Iberos, 1983: 186). Pertenece al tipo 7-A de Pereira (1988: 940). Dimensiones: alt.: 25,3 cms.; diám. boca: 16,2 cms.; diám. base: $9,5 \mathrm{cms}$. Depósito: Museo Arqueológico Nacional, colección Vives; donde figura como procedente de Archena. Bibliografía: Cabré (1925: 88 y Fig. 19-b); Bosch (1913-14: 878 y Fig. 155 izquierda); Iberos (1983: 186); Aranegui (1992: 7).

8. Vaso ibérico de borde exvasado, cuerpo ovoide y base hundida con una decoración pintada bícroma. Sobre un fondo de barníz rojo que recubre casi toda la superficie exterior del vaso aparece, en el tercio superior, una banda con el mismo acabado enmarcada por finas bandas pintadas en negro y otras en reserva. Según Cabré, en la base tiene tres círculos concéntricos pintados en rojo (Fig. $3, \mathrm{n}^{\circ}$ 5). Pertenece al tipo 5-B-I de Pereira (1988: 906), que fecha en el siglo IV a.C., con paralelos en Fuente Tojar, Puente del Obispo y en otras tumbas de Toya. Dimensiones: alt.: 14,4 cms.; diám. boca: 9,8 cms.; diám. base: 6,8 cms. Depósito: desconocido. Bibliografía: Cabré (1925: 87 y Fig. 16-a), Cuadrado (1953: 276 y Fig. 3, III-28).

9. Kalathos ibérico de borde exvasado, cuello estrangulado, hombro marcado, cuerpo cilíndrico y base levemente hundida con umbo. Tiene una decoración pintada monócroma formada por dos frisos de círculos concéntricos separados por grupos de rizos verticales, enmarcados por bandas horizontales (Lám. III, $\mathrm{n}^{\circ} 2$ ). Se incluye dentro del tipo 8-A-2 de Pereira (1988: 950), datado en el siglo IV a.C., con paralelos en la misma necrópolis de Toya y en Castellones de Ceal, para la misma cronología. Dimensiones: alt.: $23 \mathrm{cms}$; diám. boca: 16,5 cms; diám. base: $19 \mathrm{cms}$. Depósito: Museo Arqueológico Provincial de Granada, colección Gómez-Moreno. Bibliografía: Cabré (1925: 88 y Fig. 16-c); Eguaras (1950-51: $181, n^{\circ} 18$ y Fig. 116-b).

10. Cabré (1925: 88) menciona restos de kalathos decorados similares al anterior. Hoy en paradero desconocido.

11. Urna ibérica de borde exvasado, cuello estrangulado, cuerpo globular esférico y base hundida; con decoración pintada de color marrón formada por cuatro bandas horizontales en espiral, situadas en la zona media de la urna, enmarcadas por dos más anchas, debajo del cuello hay otra banda de la que penden cuartos de círculos concéntricos (Fig. 4, no 4 y Láms. III, n 6 y VII). Pertenece al tipo 7-A de Pereira (1988: 940), con una cronología del siglo IV a.C., con paralelos en Almedinilla, Cástulo, Toya y Castellones de Ceal. Dimensiones: alt.: 24,5 cms.; diám. boca: 14,3 cms.; diám. base: 6,6 cms. Depósito: Museo Arqueológico Nacional, colección Román Pulido. Bibliografía: Cabré (1925: 89).

12. Urna ibérica de borde exvasado, cuello estrangulado, cuerpo globular esférico y base hundida, con decoración pintada en color vinoso a base de cuatro finas bandas horizontales, en espiral, en la zona de diámetro máximo, enmarcadas por otras más anchas, el borde y la parte inferior 


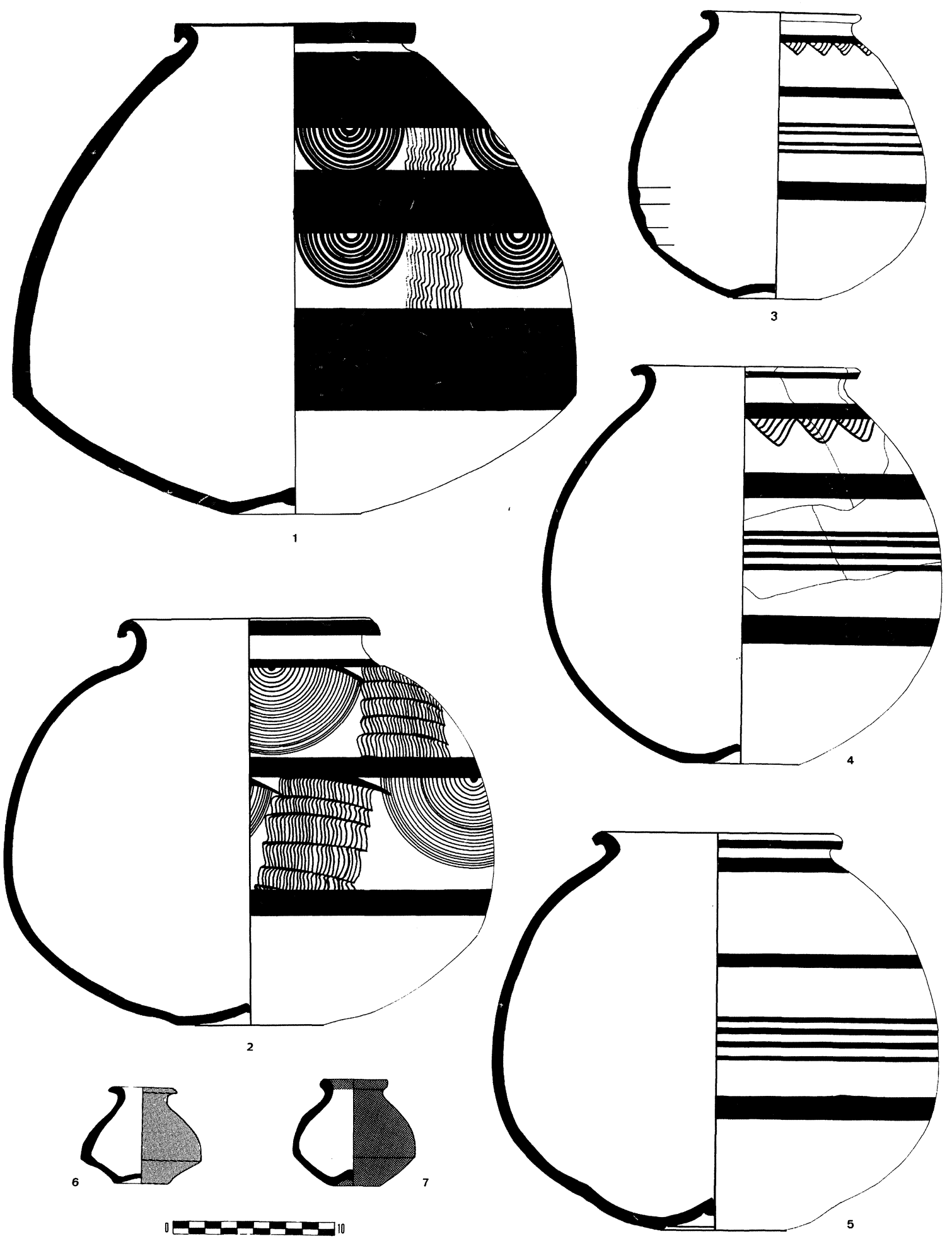

Fig. 4. Recipientes cerámicos procedentes de la cámara de Toya (dibujos del autor, excepto 1 y 3 a partir de Pereira, 1988; 6 a partir de Cabré, 1925). La urna número 3 sin escala.

T. P., 54, n. ${ }^{\circ} 1,1997$ 


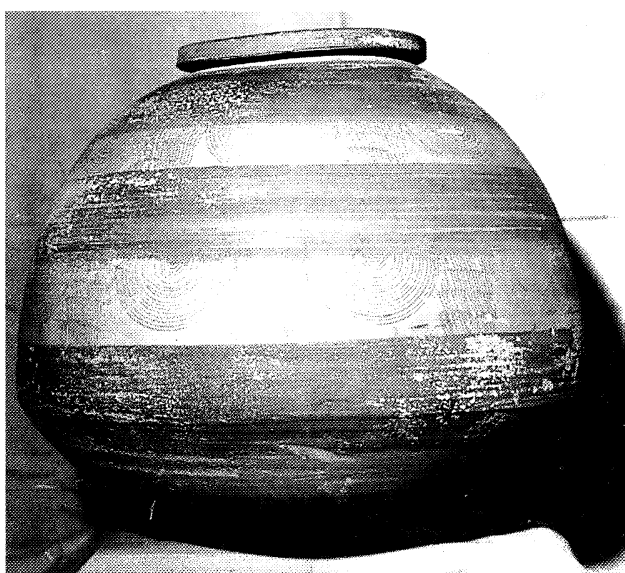

1

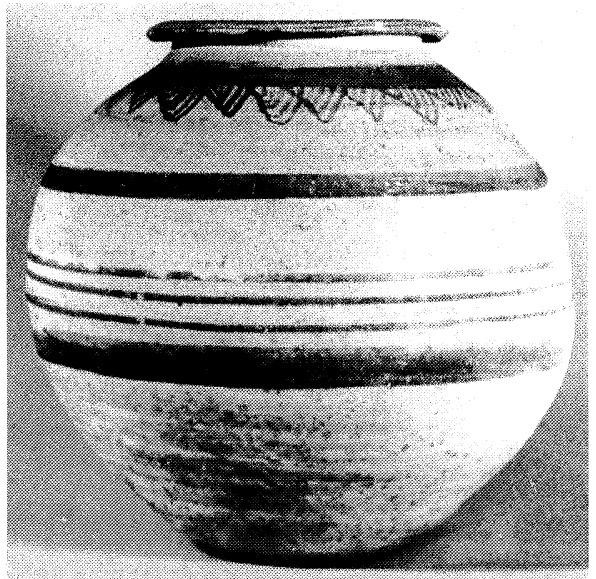

3

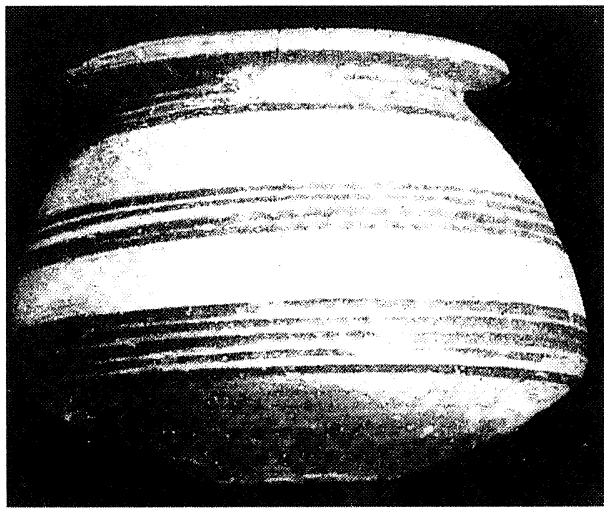

5

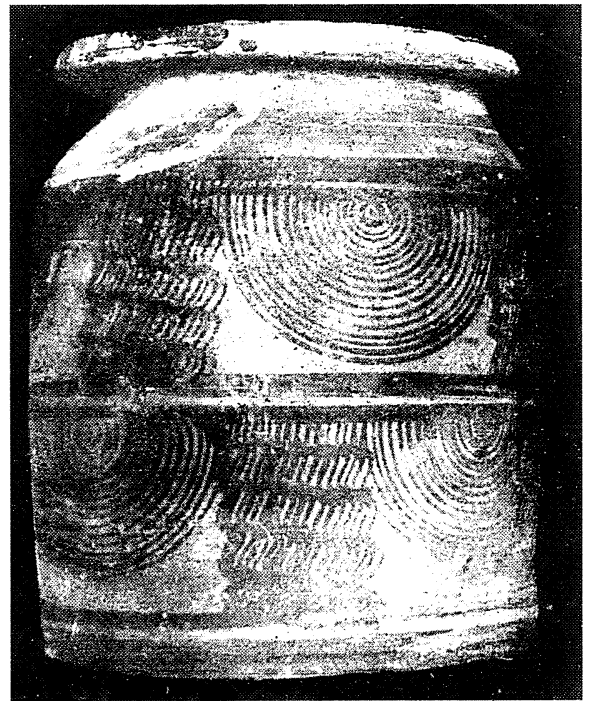

2
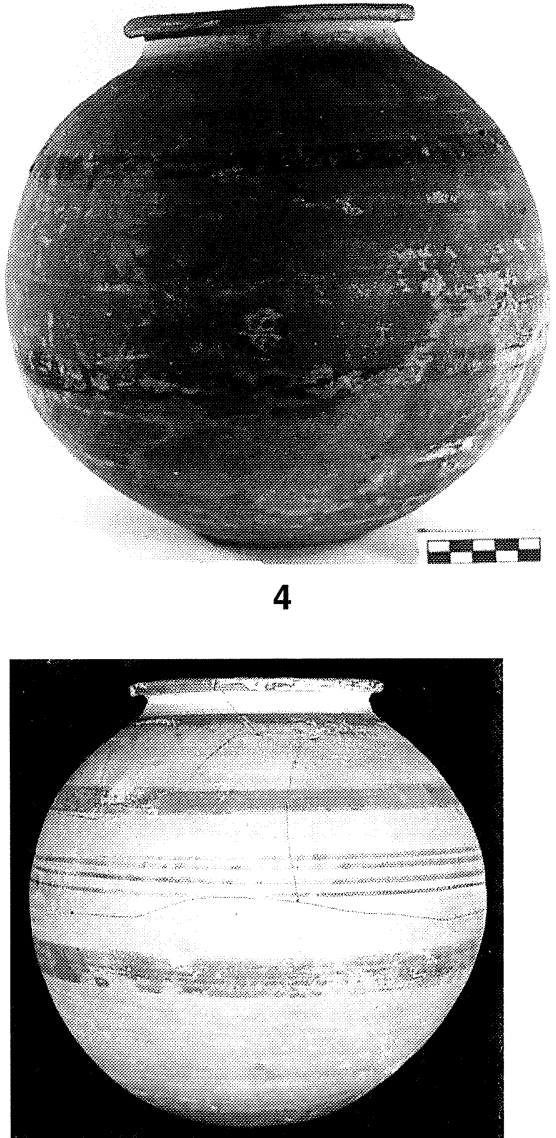

6

Lám. III. Recipientes cerámicos de la cámara de Toya (2 y 5: Cabré, 1925; 3: Pericot, 1978; 1, 4 y 6: Pereira, 1988).

T. P., 54, n. $^{\circ} 1,1997$ 
del cuello también presentan bandas del mismo color (Fig. 4, no 5 y Lám. VII). Se incluye dentro del tipo 7-A de Pereira (1988: 940). Dimensiones: alt.: 24,5 cms.; diám. boca: 14,8; diám. base: 7,4 cms. Depósito: Museo Arqueológico Nacional, colección Vives, donde figura como procedente de «Archena dudoso». Bibliografía: Cabré (1925: 89); Bosch (1913-14: 878 y Fig. 155 derecha).

13. Urna de borde exvasado, cuello estrangulado, cuerpo globular esférico, algo bitroncocóni$\mathrm{co}, \mathrm{y}$ base hundida. Tiene una decoración pintada monócroma a base de bandas horizontales situadas en los dos tercios superiores de la pieza siendo más anchas las de los extremos, de la banda situada bajo el cuello caen cuartos de círculos concéntricos (Fig. 4, n 3 y Lám. III, n 4 ). Fue publicada por Bosch como procedente del santuario del Castellar de Santisteban. Pertenece al tipo 7-A de Pereira (1988: 940). Depósito: Museo Arqueológico Provincial de Barcelona. Bibliografía: Cabré (1925: 89 y fig. 20), Bosch (1932: Fig. 295-d central), Pereira (1988: 370 y Fig. 85-3).

14. Urna de borde exvasado, cuello estrangulado, cuerpo globular esférico y base hundida. Tiene una decoración pintada monócroma a base un grupo de finas bandas horizontales, espiral, situadas en la zona de mayor diámetro de la urna, enmarcadas por otras dos más anchas, debajo del cuello hay otra banda de la que cuelgan cuartos de círculos concéntricos (Lám. III, no 3 ). Ha sido publicada como del Castellar de Santisteban por Bosch y Pericot. Pertenece al tipo 7-A de Pereira (1988: 940). Depósito: Museo Arqueológico Provincial de Barcelona. Bibliografía: Cabré (1925: 89), Bosch (1932: Fig. 295-d, derecha), Pericot (1978: Fig. 8).

15. Urna de borde exvasado, cuello estrangulado, cuerpo globular esférico con base hundida y decoración pintada monócroma a base bandas horizontales, debajo del cuello existe otra banda horizontal de la que penden cuartos de círculos concéntricos. Pertenece al tipo 7-A de Pereira (1988: 940). Depósito: Museo Arqueológico Provincial de Barcelona. Bibliografía: Cabré (1925: 89), Bosch (1932: Fig. 295-d, izquierda).

16 y 17 . Dos urnas de forma y decoración similares a las dos anteriores; formaban parte, entre otras colecciones, de las de Gómez-Moreno, Vives y Linares. Depósito: desconocido (Cabré, 1925: 89).

18. Urna de borde exvasado, cuello estrangulado, cuerpo glogular bitroncocónico y base hun-

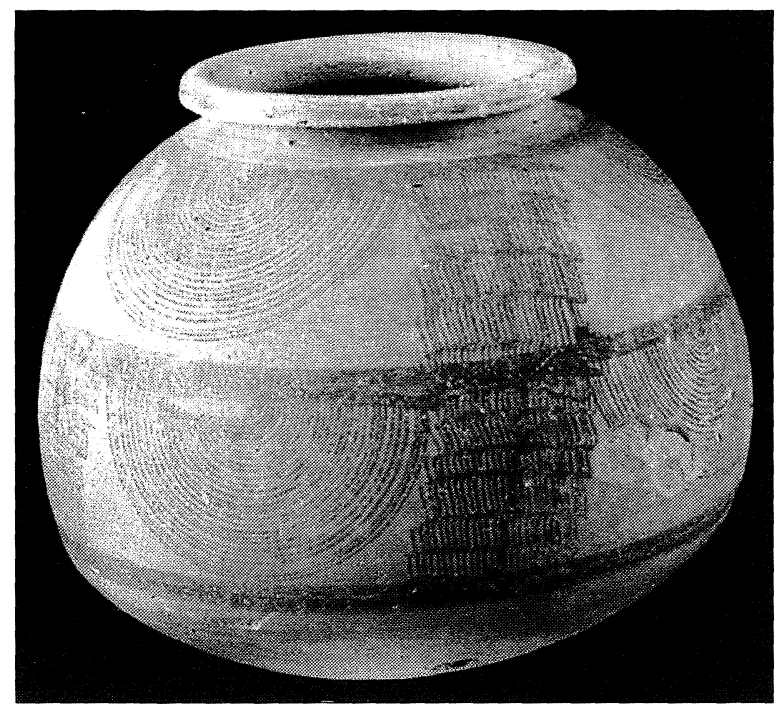

Lám. IV. Urna decorada de la cámara de Toya (Iberos, 1983).

dida, decorada con grupos de bandas horizontales pintadas monócromas. Pertenece al tipo 7-A de Pereira (1988: 940) (Fig. III, $n^{\circ}$ 5). Ha sido publicada como de Castellar de Santisteban por Bosch Gimpera y Lantier. Depósito: Museo Arqueológico Provincial de Barcelona. Según Bosch Gimpera (1915: Lám. VI) pertenecía a Cabré. Bibliografía: Cabré (1925: 89 y Fig. 19-d), Bosch (1915: Lám. VI - 6), Lantier (1917: XXXIII-6).

19. Urna de borde exvasado, cuello estrangulado, cuerpoglobular bitroncocónico y base hundida. Presenta una decoración píntada monócroma a bade de bandas horizontales. Pertenece al tipo 7-A de Pereira (1988: 940). Depósito: desconocido. Podría ser identificada en una urna de pequeñas dimensiones de la colección Vives del Museo Arqueológico Nacional, donde figura como procedente de Archena. Bibliografía: Cabré (1925: 89).

20. Urna ibérica de borde exvasado, cuello estrangulado, cuerpo globular bitroncocónico y base hundida; presenta una decoración pintada a base de grupos de finas bandas horizontales situadas sobre la carena, tercio superior y bajo el cuello. Al igual que las anteriores pertenece al tipo 7-A de Pereira. Depósito: desconocido. Bibliografía: Cabré (1925: 89)

21. Vasito caliciforme, de borde exvasado, cuello cilíndrico, cuerpo bitroncocónico y base hundida, decorado con bandas horizontales pinta- 
das de color rojo oscuro (Fig. $3 \mathrm{n}^{\circ} 6$ y Lám. V). Pertenece al tipo 12 de Pereira (1988: 988), que fecha entre mediados del siglo IV a.C. y mediados del siglo III a.C. Dimensiones: alt.: $9 \mathrm{cms}$; diám. boca $7 \mathrm{cms}$. Depósito: pertenecía a la colección García Faria y aún no ha sido localizado. Bibliografía: Cabré (1925: 88 y Fig. 16-d).

22. Vasito de borde exvasado, cuello estrangulado, cuerpo troncocónico y base hundida, decorado todo su exterior con barniz rojo de color castaño (Fig. 4, nº 7 y Lám.VII). Se incluye dentro del tipo 13-A-I de Pereira (1988: 990), que fecha en los siglos IV-III a.C., siendo una forma muy frecuente en el sector oriental de la Cuenca del Guadalquivir, bien fechada en el siglo III a.C. en la tumba 5/617 de Castellones de Ceal (Chapa y Pereira, 1991 a: 307; 1991 b: 169). Dimensiones: alt.: 6,8 cms.; diám. boca: 4,4 cms; diám. base: $3,5 \mathrm{cms}$. Depósito: Museo Arqueológico Nacional, colección Vives, donde figura como procedente de Archena. Bibliografía: Cabré (1925: 88 y fig. 17); Bosch (1913-14: 879 y Fig. 156-3; 1915: 25, nota 1).

23. Pieza semejante a la anterior (Fig. $4, n^{\circ}$ 6). Dimensiones: alt.: 7,5 cms.; diám. boca: 5,5 cms. Depósito: pertenecía a la colección GómezMoreno, aún no ha sido localizado.

Bibliografía: Cabré (1925: 88 y Fig. 17), Bosch (1915: 25, nota 1).

24. Plato de borde exvasado, cuerpo carenado y decoración de barníz rojo, con una perforación en el borde (Fig. 3, $\mathrm{n}^{\mathrm{o}} 7$ ). Se incluye dentro del tipo 17-B-I de Pereira (1988: 1014), que data desde el siglo IV a.C. Aparecieron platos semejantes en la necrópolis de Castellones de Ceal, tumbas de cámara (Chapa et alii, 1990) y del «guerrero» (Fernández-Chicarro, 1955: 94 y Fig. 39), que se fechan en el siglo III a.C. Dimensiones: alt.: 4,2 cms.; diám. boca: 26,4 cms.: diám. base: $8,4 \mathrm{cms}$. Depósito: formaba parte de la colección Gómez-Moreno, aún no ha sido localizado. Bibliografía: Cabré (1925: 88 y Fig. 18), Cuadrado (1953: 278 y Fig. 3-III-25).

25. Cuenco de borde recto de labio apuntado, cuerpo con perfil semiesférico, pie anular con umbo. Presenta una decoración pintada de color vinoso en el interior, a base de tres grupos de círculos concéntricos en espiral (Fig. 3, $\mathrm{n}^{\mathrm{o}} 13 \mathrm{y}$ Lám. VII). Pertenece al tipo 16-C-I de Pereira (1988: 1009), datado desde el siglo V a.C., con paralelos en Cástulo y Castellones de Ceal. Dimensiones: alt.: 6,3 cms.; diám. boca: 17,4 cms.; diám. base: 5,6 cms.

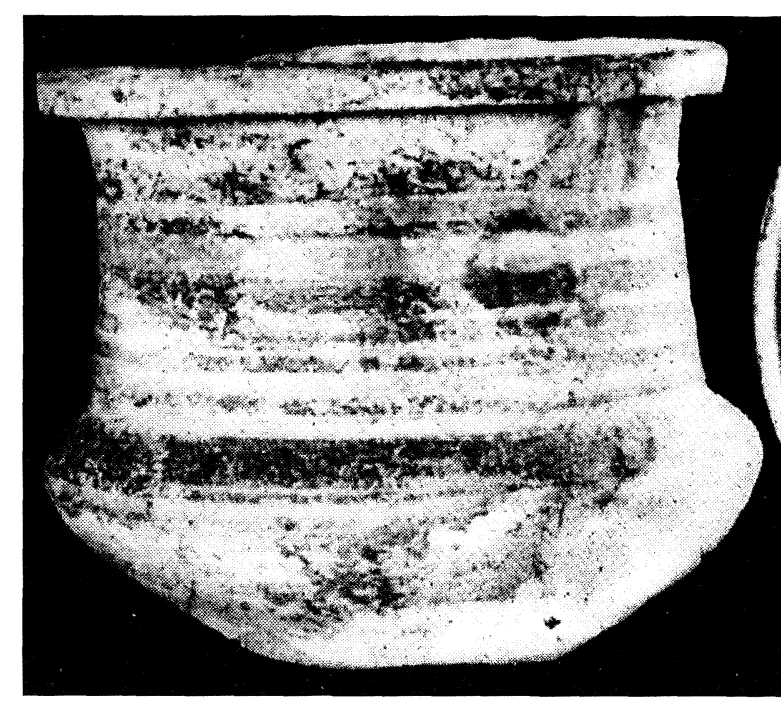

Lám. V. Vaso calciforme de la cámara de Toya (Cabré, 1925).

Depósito: Museo Arqueológico Nacional, colección Vives, donde figura como procedente de Archena. Bibliografía: Cabré (1925: 90 y Fig. 16-b); Bosch (1913-14: 879 y Fig. 156-1 y 2).

26. Cuenco de borde recto de labio apuntado, cuerpo con perfil semiesférico, pie anular con umbo. Decorado en el interior con tres grupos de círculos concéntricos en espiral. (Fig. 3, $\mathrm{n}^{\circ} 9$ y Lám. VII). Pertenece al tipo 16-C-I de Pereira (1988: 1009). Dimensiones: alt.: 5 cms.; diám. boca: $14 \mathrm{cms}$; diám. base: $4,9 \mathrm{cms}$. Depósito: Museo Arqueológico Nacional, colección Vives, donde figura como procedente de Archena. Bibliografía: Cabré (1925: 90 y Fig. 16-b); Bosch (1913-14: 879 y Fig. 156-1 y 2).

27. Cuenco de borde recto de labio apuntado, cuerpo con forma de casquete esférico, base anular con umbo. Tiene una decoración pintada en el interior de color vinoso, formada por tre grupos de círculos concéntricos en espiral (Fig. 3, $n^{\circ} 8$ y Lám. VII). Pertenece al tipo 16-C-I de Pereira (1988: 1009). Dimensiones: alt.: 6,3 cms.; diám. boca: 17,4 cms.; diám. base: 5,6 cms. Depósito: Museo Arqueológico Nacional, colección Vives, donde figura con la procedencia de Archena. Bibliografía: Cabré (1925: 90 y Fig. 16-b).

28. Cuenco de borde recto de labio apuntado, cuerpo con forma de casquete esférico, pie anular con umbo. Decorado el interior con tres grupos de círculos concéntricos en espiral pintados 


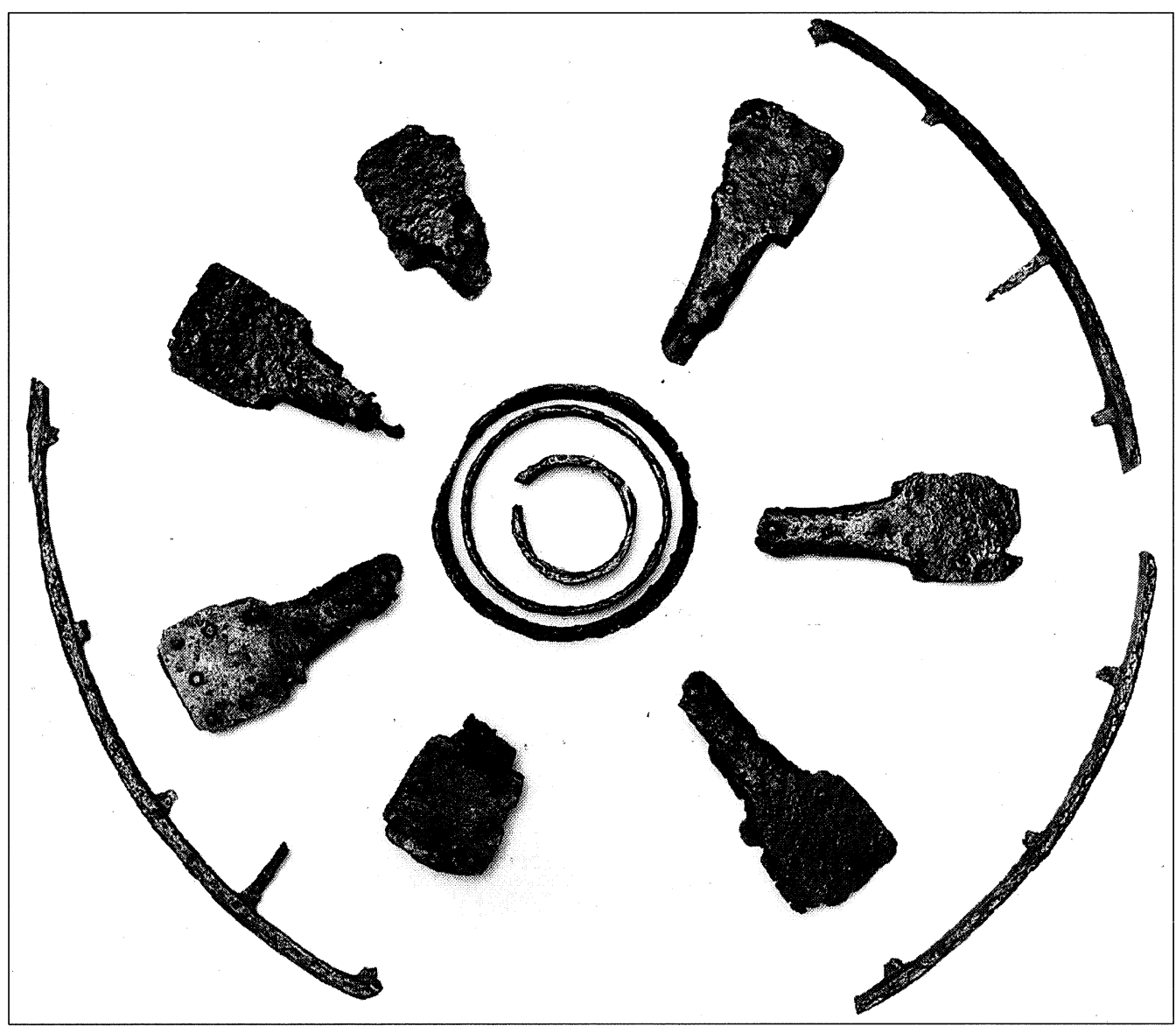

Lám. VI. Diversas piezas de una rueda de carro encontradas en el interior de la cámara de Toya (foto A, Trigo. Archivo del Museo Arqueológico Nacional)

en color vinoso (Fig. 3, $\mathrm{n}^{\mathrm{o}} 11$ ). Es del tipo 16-C-I de Pereira (1988: 1009). Dimensiones: alt.: 6,2 cms.; diám. boca: 15,6 cms.; diám. base: 5,3 cms. Depósito: Museo Arqueológico Provincial de Barcelona, donde figura como procedente de Villaricos (Almería). Bibliografía: Cabré (1925: 90 y Fig. 16-b).

29. Cuenco de borde recto de labio apuntado, cuerpo con forma de casquete esférico, pie anular con umbo. En el interior presenta una decoración pintada de color vinoso a base de tres grupos de círculos concéntricos en espiral (Fig. 3, $\mathrm{n}^{\circ}$ 10). Pertenece al tipo 16-C-I de Pereira (1988: 1009). Dimensiones: alt.: $6,2 \mathrm{cms}$.; diám. boca: 14,5 cms.; diám. base: 5,6 cms. Depósito: Museo Arqueológico Provincial de Barcelona, donde figura como procedente de Villaricos. Bibliografía: Cabré (1925: 90 y Fig. 16-b).

30. Dos fragmentos de un cuenco de borde recto de labio apuntado, cuerpo con forma de casquete esférico, pie anular con umbo. Tiene una decoración pintada de color vinoso en el interior a base de tres grupos de círculos concéntricos en espiral (Fig. $3, \mathrm{n}^{\circ} 12$ ). Pertenece al tipo 16-C-I de Pereira (1988: 1009). Dimensiones: alt.: 6,3 cms.; diám. boca: 14,6 cms.; diám. base: 5,2 cms. Depósito: Museo Arqueológico Provincial de Barcelona, donde figura como procedente de Villaricos. Bibliografía: Cabré (1925: 90 y Fig. 16-b).

31. Cabré cita fragmentos de otros cuencos similares que permanecen en paradero desconocido.

32 a 37. Seis cajas de piedra en diferente estado de conservación y fragmentación. Tendrían forma rectangular con cuatro patas de sección cuadrangular y tapas con forma de tejado a doble vertiente. Todas en paradero desconocido. Bibliografía: Cabré (1925: 85 y Fig. 14). 


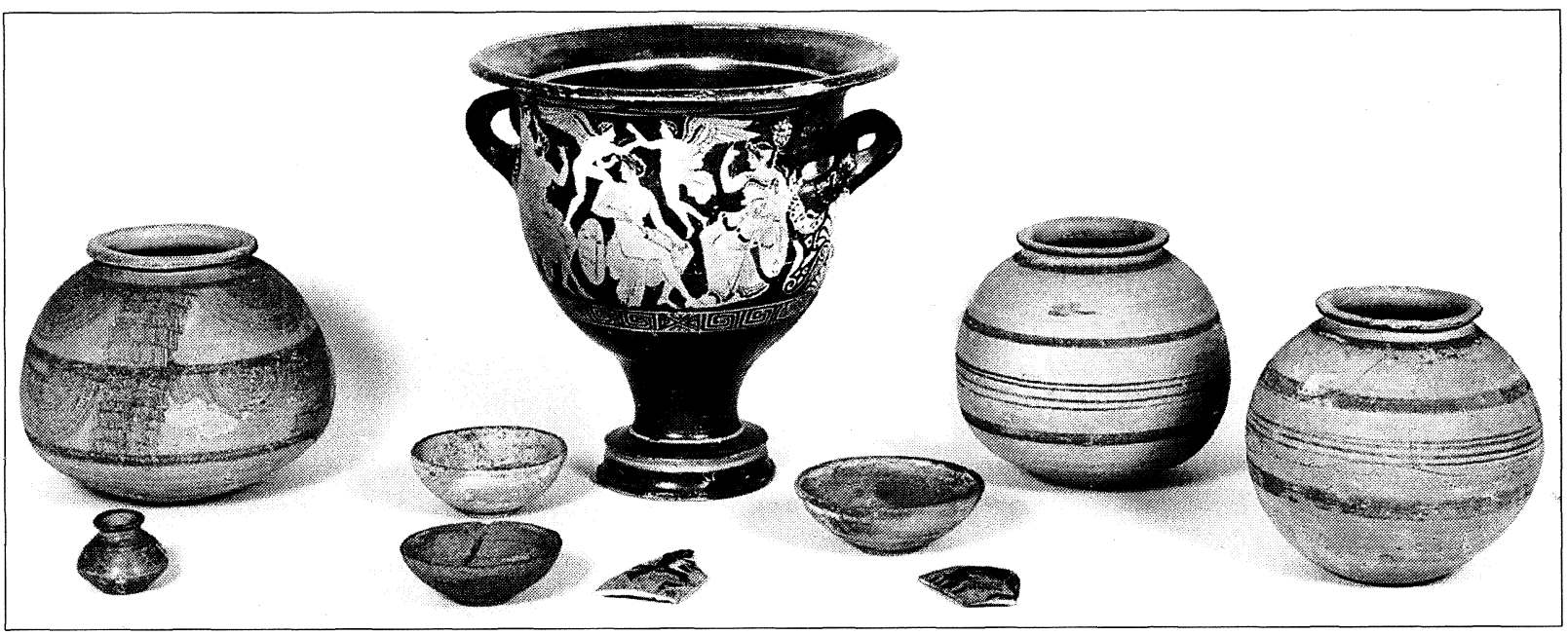

Lám. VII. Conjunto de recipientes cerámicos depositados en el M.A.N. procedentes de la cámara de Toya (fotoA. Trigo. Archivo del Museo Arqueológico Nacional.).

38. Disco de bronce con una cabeza de felino repujada y cincelada en el centro, junto al borde hay dos líneas grabadas. Según Cabré está partido intencionalmente en dos mitades. Puede interpretarse como un umbo de un escudo o una pátera (Fig. 3, $\mathrm{n}^{\circ}$ 14). Dimensiones: diámetro $13 \mathrm{cms}$. Depósito: pertene a la colección Cabré, aún no ha sido localizado. Bibliografía: Cabré (1925: 91 y Fig. 23).

39. Fragmento de borde de una sítula de bronce. Dimensiones: diámetro boca: $12 \mathrm{cms}$. Depósito: desconocido. Bibliografía: Cabré (1925: 91).

40. Fragmento de un vaso de bronce con anillos relevados hacia el exterior, en paradero desconocido.

41. Fragmentos pertenecientes a la empuñadura y hoja de una falcata. Depósito: Museo Joan Cabre (Calaceite, Teruel).

42. Fragmento de empuñadura de espada de antenas, posiblemente del tipo IV o Alcacer-doSal de Quesada (1991: 635-634). Depósito: Museo Joan Cabre (Calaceite, Teruel).

43. Fragmentos pertenecientes a varias vainas de espadas, no localizados.

44. Fragmento de regatón de hierro, no localizado.

45. Casco de hierro tipo Montefortino, que ha de ser fechado hacia el siglo III a. C. si seguimos a Quesada (1992), o si comparamos esta pieza con el casco de hierro de la cámara de Ceal (Cha- pa et alii, 1990; García, 1993: 105). Depósito: Museo Joan Cabre (Calaceite, Teruel).

46. Varias piezas de hierro pertenecientes a dos ruedas de carros. Fernández-Miranda y Olmos (1986: 71) clasificaron once fundas metálicas de radios, ocho belas sencillas, dos bocines, varios fragmentos de llantas metálicas algunas de ellos doblados intencionalmente, varios clavos y fragmentos no identificables (Lám. V). Piezas similares se han encontradao en la tumba 176 de la necrópolis de Baza (Presedo, 1982: 237 y Figs. 197-198). Depósito: Museo Arqueológico Nacional, colección Cabré. Bibliografía: Cabré (1925: 90-91 y Fig. 21); Fernández-Miranda y Olmos (1986: 70-74 y Láms. VIII y IX).

47. Varias cuentas de collar de plata y vidrio de colores azul oscuro y amarillo, no localizadas. Depósito: desconocido. Bibliografía: Mergelina (1943-44: 18).

\section{CONCLUSIONES}

Como se ha podido ver la cronología de las diferentes piezas remite a una primera utilización de la cámara durante la primera mitad del siglo IV a.C., prolongándose hasta el siglo III si nos atenemos a la cronología de ciertos tipos cerámicos y del casco de hierro. Dado que las cámaras estan concebidas como panteones familiares o de linajes, es lógico pensar en un empleo prolonga- 
do a lo largo del tiempo, como se documenta en Galera. En todo caso hemos de resaltar la uniformidad de los tipos cerámicos, hecho generalizado a partir del siglo IV a.C. en otras necrópolis, como la de Castellones de Ceal. Otra posible interpretación para tal uniformidad de formas e, incluso de motivos decorativos, es que estemos ante un determinada producción cerámica manufacturada especialmente para servir de recipientes funerarios de los personajes enterrados en esta tumba. La cámara de Toya, como cualquier enterramiento ibérico con 2 ó más individuos, presenta restos de un importante equipo armamentístico con piezas tan significativas como el carro y el casco, elementos vinculados al importante estamento militar que, en la Alta Andalucía, se entierra en tumbas de cámara o en fosas complejas.

\section{AGRADECIMIENTOS}

Deseo expresar mi agradecimiento a todas las personas que han hecho posible la elaboración de este trabajo, en especial a Teresa Chapa, Juan Pereira, Julia Sánchez y Esperanza Manso. A José $\mathbf{M}^{\mathrm{a}}$ Abenza y Alicia Torija por su apoyo incondicional. A Fernando Quesada Sanz por permitirme utilizar los datos de su tesis doctoral inédita «El armamento ibérico».

\section{BIBLIOGRAFÍA}

Almagro Basch, M. (1975): «Las raíces del arte ibérico». Papeles del Laboratorio de Arqueología de Valencia, 11: 251-279. Valencia.

Almagro Gorbea, M. (1982): «Tumbas de cámara y cajas funerarias ibéricas. Su interpretación socio-cultural y la delimitación del área ibérica de los bastetanos». Homenaje a Conchita Fernández Chicarro. Ministerio de Cultura. Madrid: 249-257.

Aranegui Gascó, C. (1992): La cerámica ibérica. Cuadernos de Arte Español, 34. Historia 16. Madrid.

BLÁNQUEZ PÉREZ, J.J. (1992): «Las necrópolis ibéricas en el Sureste de la Meseta». En J.J. Blánquez Pérez y V. Antona del Val (coords.): Congreso de Arqueología Ibérica. Las necrópolis. Serie Varia, 1. Universidad Autónoma. Madrid: 235-278.

BlÁZQuez, J.M. a (1960): «La cámara sepulcral de Toya y sus paralelos etruscos». Oretania, 5: 233-237. Linares.

- (1986): «El influjo de la cultura semita (fenicios y cartagineses) en la formación de la cultura ibérica». Aula Orientalis, 4: 163-178. Barcelona.
Bosch GIMPERA, P. (1913-14): «Adquisicions de la colleció Vives, de Madrid». Anuari de l'Institut d'Estudis Catalans: 875-879. Barcelona.

- (1915): El problema de la cerámica ibérica. Memorias de la Comisión de Investigaciones Paleontológicas y Prehistóricas, 7. Museo Nacional de Ciencias Naturales. Madrid.

- (1932): Etnología de la Península Ibèrica. Ed. Alpha. Barcelona.

CABRÉ, J. (1925): «Arquitectura hispánica. El sepulcro de Toya». Archivo Español de Arte y Arqueología, 1: 73-101. Madrid.

CABRÉ, J. y Motos, F. de (1920): La necrópolis ibérica de Tútugi (Galera, provincia de Granada). Junta Superior de Excavaciones y Antigüedades, 25. Madrid.

CAZABÁn, A. (1915): «La necrópolis de Toya». Don Lope de Sosa, III (32): 240-242.

- (1926): «La cámara sepulcral ibérica del Cerro de la Horca. Sus vicisitudes y su defensa». Don Lope de Sosa, XIV (166): 232-236.

- (1928): «La cámara sepulcral hispánica del Cerro de la Horca (Peal de Becerro) y su vigilancia, defensa y conservación». Don Lope de Sosa, VI (190): 336337.

Chapa Brunet, T. (1980): La escultura zoomorfa ibérica en piedra. 2 vols. Universidad Complutense. Madrid.

Chapa, T.; Madrigal, A. y Pereira, J. (1990): «La cámara funeraria de los Castellones de Ceal (Hinojares, Jaén)». Verdolay, 2: 81-86. Murcia.

Chapa, T. y Pereira, J. (1991a): «Excavación arqueológica sistemática de Los Castellones de Ceal. Campaña 1987». Anuario Arqueológico de Andalucía /1989, II: 304-308. Sevilla.

- (1991b): «Los Castellones de Ceal (Hinojares, Jaén). Informe de la campaña de 1989». Anuario Arqueológico de Andalucía/1989. II: 165-170. Sevilla.

Chapa, T.; Pereira, J. y Madrigal, A. (1993): «Mundo ibérico y mundo púnico en la Alta Andalucía». 1 ${ }^{\circ}$ Congresso de Arqueología Peninsular. Actas II (Oporto, 1993). Trabalhos de Antropologia e Etnologia, 33 (3-4): 411-426.

Cuadrado, E. (1953): «Materiales ibéricos: cerámica roja de procedencia incierta». Zephyrus, IV: 265309. Salamanca.

EguARAs IbÁÑEZ, J. (1950-51): «Museo Arqueológico de Granada». Memorias de los Museos Arqueológicos Provinciales, XI-XII: 179-185. Madrid.

FERNÁNDEZ-CHICARRo, C. (1955): «Prospección arqueológica en los términos de Hinojares y La Guardia (Jaén)». Boletín del Instituto de Estudios Giennenses, 4: 89-99. Jaén.

FERnÁNDEZ DE Avilés, A. (1942): «El aparejo irregular de algunos monumentos marroquíes y su relación con el de Toya». Archivo Español de Arqueología, 15: 344347. Madrid.

T. P., 54, n. ${ }^{\circ} 1,1997$ 
- (1943): «Notas sobre la necrópolis ibérica de Archena (Murcia)». Archivo Español de Arqueología, 16: 115-121. Madrid.

FERnÁNDEZ-Miranda, M. y Olmos, R. (1986): Las ruedas de Toya y el origen del carro en la Península Ibérica. Museo Arqueológico Nacional. Catálogos y monografías, 9. Madrid.

García y Bellido, A. (1935): «La cámara sepulcral de Toya (Jaén) y sus paralelos mediterráneos». Actas y Memorias de la Sociedad Española de Antropología, Etnología y Prehistoria, 14: 67-106. Madrid.

- (1936): Los hallazgos griegos en España. Centro de Estudios Históricos. Madrid.

- (1948): Hispania Graeca. 2 vols. Instituto Español de Estudios Mediterráneos. Barcelona.

- (1963): «Arte ibérico». En R. Menéndez Pidal (dir.): Historia de España, 1(3). Espasa Calpe. Madrid: 371-675, $2^{\mathrm{a}}$ ed.

García-Gelabert, M. ${ }^{a}$ P. (1991): «Los enterramientos de la Alta Andalucía (España): sus relaciones con el Mediterráneo Oriental». Atti del II Congresso Internazionale di Studi Fenici e Punici (Roma, 1987). Consiglio Internationale delle Recherche: 889-895.

García-Mauriño MuzQuiz, J. (1993): «Los cascos de tipo Montefortino en la Península Ibérica. Aportación al estudio del armamento de la $\mathrm{II}^{\mathrm{a}}$ Edad del Hierro». Complutum, 4: 95-146. Madrid.

Iberos (1983): Los Iberos. Ministerio de Cultura. Madrid.

Laínez AlCAlÁ, R. (1926): «Nuevas rutas del turismo. El Alto Guadalquivir. I». La Epoca. Año VI, nº 288. Sábado 31-VII-1926. Supl. al no 27010.

LANTIER, R. y CABré Aguiló, J. (1917): El Santuario Ibérico de Castellar de Santisteban. Memorias de la Comisión de Investigaciones Paleontológicas y Prehistóricas, 15. Museo Nacional de Ciencias Naturales. Madrid.
MéLIDA, J.R. (1918): «Toro ibérico de piedra, procedente de la necrópoli de Tugia». Museo Arqueológico $\mathrm{Na}$ cional. Adquisiciones en 1917. Notas descriptivas. Madrid.

- (1919): «Crátera báquica italogriega, encontrada en el Cerro de la Horca, en término de Peal del Becerro (Jaén)». Museo Arqueológico Nacional. Adquisiciones en 1918. Notas descriptivas. Madrid.

MergelinA, C. de (1943-44): «Tugia. Reseña de unos trabajos». Boletín del Seminario de Estudios de Arte y Arqueología, 10: 13-32. Valladolid.

Nicolini, G. (1973): Les Ibères. L'Art et la Civilisation de l'Espagne Antique. Fayard. Paris.

Pericot, L. (1978): Cerámica ibérica. Ed. Poligrafa. Barcelona.

Pereira Sieso, J. (1988): La cerámica pintada a torno en Andalucía entre los siglos VI y II a.d.C. Cuenca del Guadalquivir. Colección tesis doctorales N²406/88. Universidad Complutense. Madrid. 2 vols.

Presedo Velo, F. J. (1982): La necrópolis de Baza. Excavaciones Arqueológicas en España, 119. Madrid.

Quesada SAnZ, F. (1992): «El casco de Almeciles (Granada y la cuestión de los cascos de tipo «Montefortino» en la Península Ibérica».Verdolay, 4: 65-73. Murcia.

SÁnchez, J.; Mayoral, V.; Chapa, T.; Madrigal, A. y PeREIRA, J. (e.p.): «Arqueología de la arquitectura en la cuenca alta del Guadalquivir. Cámaras funerarias y estructuras de habitación en época ibérica». II Congreso de Arqueología Peninsular (Zamora, 1996). Ed. Fundación Rey Alfonso Enrique. Zamora.

SÁnCHEZ FERnÁNDEZ, C. (1992): El comercio de productos griegos en Andalucía Oriental en los siglos $V y$ IV a.C.: estudio tipológico e iconográfico de la cerámica. Colección tesis doctorales $\mathrm{n}^{\circ} 1495 / 92$. Universidad Complutense. Madrid.

TRÍAS DE ARribAS, G. (1967-68): Cerámicas griegas de la Península Ibérica. The William L. Bryant Foundation. Valencia. 2 vols. 